years ago. There is no report of any damage, and further details of this shock are awaited from Spain.

The United States Coast and Geodetic Survey, in co-operation with Science Service and the Jesuit Seismological Association, has determined the epicentres of the earthquakes of May 19 and June 3. The former, from the readings of seismograms obtained at sixteen observatories, had an epicentre near lat. $40 \cdot 2^{\circ} \mathrm{N}$., long. $126 \cdot 8^{\circ} \mathrm{W}$., which is off northern California. The latter occurred at $13 \mathrm{~h}$. $05.6 \mathrm{~m}$. G.M.T. from an epicentre near lat. $8 \cdot 3^{\circ} \mathrm{N}$., long. $82 \cdot 6^{\circ} \mathrm{W}$., which is in Chiriqui Province, Panama.

During April, May and June nineteen earthquakes were registered on the seismographs at King's College Observatory, Aberdeen, Scotland. The strongest of these was on May 19, when an earthquake registered at $15 \mathrm{~h}$. $18 \mathrm{~m}$. 34s. G.M.T. and attained a maximum ground amplitude at Aberdeen of $20 \mu$ on the north-south component.

At Binstead, Isle of Wight, Mr. E. W. Pollard registered eleven earthquakes during June; his machine was undergoing repairs during June 26 and 27.

\section{CLOSURE AND PARTIAL SEPARATION OF A METALLIC CONTACT}

$\mathrm{T}$ HE problems associated with contacts between nominally clean metallic surfaces approaching and separating normally may be divided into two groups according to whether the path between the surfaces is metallic or gaseous. A paper by Dr. Alan Fairweather (J. Inst. Elec. Eng., 92, Pt. 1, No. 56 ; August 1945) is concerned with the first of these groups. The field of interest may be further subdivided, as it includes both the phenomena associated with nominally static contacts and those relevant to separating contacts up to the instant when the metallic path between the contacts ceases to exist.

In the first part of the paper, all the effects encountered in the change of resistance with current and mechanical pressure are shown to be predictable on the basis of the existence of contact spots. The extents of resistance changes are directly related to the mechanical pressure. A fresh technique is described, by means of which the existence of the spots may be demonstrated and a lower limit assigned to their number. The influence of the rate of current loading is examined, and further verification of the plastic character of the yielding process is furnished. The measurements described relate to one particular contact material, a platinum iridium alloy, and to one surface finish. They cover much wider ranges of pressures and voltages than are encountered in practice, and permit identification of all the significant events observable in a normal laboratory atmosphere. This range of observations is bounded only by limits at which effects cease to be those relovant to a clean metallic contact. One limit, attributable to surface films, not necessarily due to tarnishing, is encountered at very small pressures and voltages: the other appears at higher voltages which, if exceeded, result ultimately in glowing and fusion of the contact surfaces.

The second part of the paper is concerned with the unequal wear of the two members of a contact pair, termed 'selective erosion' or 'unbalanced erosion'; this is frequently accompanied by a gain of material by one member at the expense of the other. In severe cases one member may develop a large pip while the other produces a corresponding crater : the contacts may then lock together. Hitherto, experience has suggested that such pips and craters occur in a random manner and that neither seems to be associated with a particular contact polarity. The work described presents a now and simplified approach to the problem. It is suggested that, in general, and perhaps more especially when quenching is permissible, unbalanced erosion results from, or can be made to result from, two main causes: first, the molten metallic bridge joining the contacts when only partly separated, and secondly, the arc. The sense of arc erosion is always the same, independent of the metal, whereas that of bridge erosion depends on the sign of the Thomson coefficient of the metal near its boiling point. Thus, metals for which the senses of the bridge and are erosion are the same can only exhibit one sense of erosion; but those for which they are opposite can exhibit both senses, or even none at all, deperrding on which effect predominates due to appropriate circuit conditions. 'This leads to the idea of alloys so designed as to possess a zero Thomson coefficient near their boiling point, which would therefore give equal bridge erosion of both contact members. Progress has been made in the development of such alloys. The remaining unbalanced are erosion would then be reduced as far as possible by the use of an appropriate quench. Such alloys would, of course, have to satisfy all the conventional requirements for contact materials and, if possible, one more: even with a quench, the possibility of slight residual arcing cannot be neglected, so that it would be desirable, when selecting metals for the development of balanced bridge erosion alloys, to do so from those which do not readily support an arc.

\section{FORTHCOMING EVENTS}

\author{
Saturday, November 3
}

association of Austrian Engineers, Chemists and Scientific WORKERS IN GREAT BRITAIN (at the Chemical Society, Burlington House, Piccadilly, London, W.1), at 3 p.m.-Meeting of British and Austrian scientists in support of the restoration of Science in Austria. Monday, November 5

FARMERs' CLUB (at the Royal Empire Society, Craven Street, Strand, London, W.C.2), at 2.30 p.m.-Prof. T. Dalling: "Sterility in Cattle".

SOCIETY OF ENGINEERS (at the Geological Society, Burlington House, Piccadilly, London, W.1), at 5 p.m.-Mr. M. 'Spindel and Mr. R. T. Quinn: "'Improvements on Portland Cements and Concrete -Past, Present and Future".

\section{Tuesday, November 6}

British Psychologicai Society, Industrial Section (at the War office Cinema, Curzon Street House, Curzon Street, London, W.1) at 1.15 p.m.- Lieut.-Colonel B. Ungerson: "Motion Study Applied to Military Problems" (with Film illustrations).

ROYAI INSTITUTION (at 21 Albemarle Street, Iondon, W.1), at 5.15 p.m.-Dr. A. Müller: "50th Anniversary of the Discovery of X-Rays", (i) "The Background of Röntgen's Discovery".

QUEKETT MICROSCOPICAL CLUB (at the Royal Society, Burlington QUERETT MIOR0SCOPICAL ClUB (at the Royal Society, Burlington
House, Piccadilly, London, W.1), at 6.30 p.m.-Mr. E. A. Robins : "Touse, Piccadilly, I0

Wednesday, November 7

ROYAL SOCIETY OF ARTS (at John Adam Street, Adelphi, London, ROYAL SOCIETY OF ARTS (at John Adam Street, Adelphi, London, of the Prince Consort on Science" (Inaugural Address).

INSTITUTION OF ELECTRICAI ENGINEERS, RADIO SECTION (at Savoy Place, Victoria Embankment, London, W.C.2), at 5.30 p.m.- Mr. R. J.'Clayton, Dr. J. E. Houldin, Dr. H.' R. L. Lamont and Mr. W. E. Willshaw: "Radio Measurements in the Decimetre and Centimetr Wavebands".

SOCIETY OF PURUTC ANALYSTS AND OTHER ANALYTIOAI ChFMISTS (at the Chemical Society, Burlington House, Piccadilly, London, W.1), (at 6 p.m-Mr. T. W. Good win and Prof R. A. Morton: "The Determat 6 p.m. - Mr. T. W. Goodwin and Prof. R. A. M.orton: "The Determination of Carotene and Vitamin A in Butter and Margarine"; "Mr. Photoelectric Method of Assaying Vitamin A in Margarine". 